\title{
Respon Pertumbuhan Bibit Picrasma javanica Blume terhadap Intensitas Naungan dan Media Tanam
}

\author{
Growth Response of Picrasma javanica Blume Seedling to Different Shading Intensities \\ and Medium
}

\author{
Ninik Setyowati dan Ning Wikan Utami*
}

Bidang Botani, Puslit Biologi-LIPI, Cibinong Science Center, Jl. Raya Jakarta-Bogor Km 45, Cibinong 16911

E-mail: wikan.utami@yahoo.com*Penulis untuk korespondensi

\begin{abstract}
Study on the growth response of Picrasma javanica Blume seedling to different shading intensities and medium was conducted at the Experimental Garden of Treub Laboratory, Research Centre for Biology, LIPI from June to December 2007. The research was arranged using Factorial in Completely Randomized Block Design with 2 factors and 5 replications. The first factor was shading intensities which were $0 \%$ (N0, without shading, average light intensities 39300 lux), 25\% (N1, average light intensities $16430 \mathrm{lux}$ ), and $50 \%$ (N2, average light intensities $5867 \mathrm{lux}$ ), respectively and the second factor was medium (combinations of soil: manure:compost) with 6 levels were M1= 1:0:0, M2= 1:1:1, M3= 1:1:2, M4= 3:1:1, M5= 1:2:1, and M6= 2:1:1. The result showed that the N0 treatment (without shading) resulted the best growth response of Picrasma javanica Blume seedling, as showe in all parameters observed (plant height $27.11 \mathrm{~cm}$; leaf number 15.57; diameter of trunk $4.32 \mathrm{~mm}$; and root length of $15.97 \mathrm{~cm}$, shoot dry weight of $1.762 \mathrm{~g}$, root dry weight of $0.688 \mathrm{~g}$ and seedling quality index of 0.277$)$. The growth media treatment of M5 (1-soil:2 manure:1 compost) showed the positive response on the growth of seedling better than other treatments and different with control (M1, soil media), with parameters were observed which was plant height $25.05 \mathrm{~cm}(\mathrm{M} 1=19.10 \mathrm{~cm})$; leaf number $16.53(\mathrm{M} 1=$ 9.20); diameter of trunk $3.89 \mathrm{~mm}(M 1=2.76 \mathrm{~mm})$; root lengh $15.23 \mathrm{~cm}(M 1=12.71$ $\mathrm{cm})$; shoot dry weight $1.58 \mathrm{~g}(\mathrm{M} 1=0.663 \mathrm{~g})$; root dry weight $0.51 \mathrm{~g}(\mathrm{M1}=0.221 \mathrm{~g})$ and seedling quality index $0.220(\mathrm{M} 1=0.089)$. The combination treatment of $\mathrm{NO}$ (without shading) and media M5 (1:2:1) gave the best response on the growth of Picrasma seedling (plant height $36.14 \mathrm{~cm}$; leaf number 28.2; diameter of trunk $4.7 \mathrm{~mm}$; and root length $16.7 \mathrm{~cm}$, shoot dry weight $3 \mathrm{~g}$ and root dry weight $0.92 \mathrm{~g}$ ).
\end{abstract}

Key words: Growth, seedling, shading, medium, Picrasma javanica Blume

Diterima: 17 Juli 2008, disetujui: 12 November 2008

\section{Pendahuluan}

Ki pahit (Picrasma javanica Blume) yang termasuk dalam suku Simaroubaceae adalah salah satu jenis tumbuhan yang berpotensi untuk pengobatan penyakit malaria. Wirdateti dan Roemantyo (1992) melaporkan adanya 13 jenis tumbuhan yang dimanfaatkan oleh penduduk Dumoga Bone di Sulawesi Utara untuk mengobati malaria. Selanjutnya,
Uji (1995) juga melaporkan bahwa sebanyak 39 jenis tumbuhan telah dimanfaatkan untuk mengobati penyakit malaria. Sebagian besar dari jenis-jenis ini tumbuh liar di hutan dan di semak belukar. $P$. javanica Blume merupakan salah satu jenis yang perlu mendapat perhatian karena potensinya dan keberadaannya di alam yang sudah jarang ditemui (Uji, 1995), dan keberadaannya dilaporkan terancam punah (Bahktiar, 2005). 
Ekstrak daun, biji, batang dan akar $P$. javanica Blume mengandung senyawa anti bakteri (Arbain et al., 2005). Komponen kimia pada ekstrak kulit batang ki pahit adalah alkaloid, flavonoid, saponin, tannin, dan steroid/triterpenoid (Praptiwi et al., 2007).

Disamping khasiatnya sebagai obat, $P$. javanica Blume mempunyai biji yang masih rendah daya perkecambahannya (10-15\% pada suhu $30-32^{\circ} \mathrm{C}$ ). Vigor semai yang mendapatkan pretreatment $4,8^{\circ} \mathrm{C}-20,8^{\circ} \mathrm{C}$ lebih tinggi dan seragam antara 90 - 100\% (Sutarno dan Utami, 2007).

Saat ini keberadaan $P$. javanica Blume dikhawatirkan karena sulit didapatkan di lapangan, walaupun dilaporkan bahwa penyebarannya sangat luas yakni dari ketinggian 150-1400 m (Heyne, 1987), bahkan sampai ketinggian $1500 \mathrm{~m}$ (Hidayat, 2003). Kelangkaan jenis-jenis tumbuhan obat di alam disebabkan karena cara pengambilan material obatnya pada umumnya dilakukan dengan menebang pohon serta belum adanya usaha pembudidayaan (Uji, 1995). Hal demikian mengancam keberadaan $P$. javanica, mengingat bahan tanamannya diburu untuk bahan obat malaria tanpa diimbangi usaha pembudidayaannya. Oleh karena itu perlu dicari teknik perbanyakan bibit yang tepat guna dan mudah dilakukan. Perbanyakan tanaman dipengaruhi oleh faktor lingkungan seperti media, iklim mikro, ketersediaan air, suhu udara, cahaya dan ketersediaan hara (Lakitan, 1995). Setiap faktor mempunyai pengaruh berbeda terhadap pertumbuhan bibit. Pertumbuhan bibit akan menjadi baik apabila hara cukup tersedia, sedang cahaya pengaruhnya adalah sebagai sumber energi untuk tumbuh. Dengan mengkombinasikan kedua faktor tersebut diharapkan dapat memberi pengaruh yang baik terhadap pertumbuhan bibit $P$. javanica Blume. Sedangkan media tumbuh yaitu tanah, pupuk kandang dan kompos dipilih berdasarkan bahwa persyaratan media untuk pembibitan antara lain remah, porius dan cukup bahan organik (Hartmann et al., 1997). Sehingga penelitian untuk mengetahui respon pertumbuhan bibit Picrasma javanica Blume terhadap penggunaan naungan dan media tanam yang berbeda masih diperlukan.
Dari penelitian ini diharapkan dapat diperoleh informasi tentang intensitas naungan yang optimal dan media tumbuh yang tepat serta kombinasi ke duanya untuk mempercepat dan meningkatkan pertumbuhan bibit ki pahit. Selain itu diharapkan pula untuk menghasilkan bibit yang berkualitas dengan teknologi yang dapat dijangkau, yaitu mudah dan murah (tepat guna) supaya dapat diterapkan oleh petani (Baharsyah, 1996).

\section{Metode Penelitian}

Percobaan dilakukan di Kebun Percobaan Treub, Puslitbang Biologi, LIPI, Bogor pada bulan Juni - Desember 2007. Bahan penelitian yang digunakan adalah semai hasil perbanyakan dari biji yang diperoleh dari tanaman koleksi Kebun Raya Bogor. Semai berumur 4 minggu dengan pertumbuhan seragam, tinggi $8-10 \mathrm{~cm}$ dan berdaun 3-5, ditanam dalam polibag dengan ukuran $20 \times 30$ $\mathrm{cm}$, yang sudah diisi media tanam (sesuai perlakuan), kemudian diletakkan dibawah intensitas naungan sesuai dengan perlakuan.

Percobaan dilakukan dengan menggunakan Rancangan Acak Kelompok Lengkap yang disusun secara faktorial, 2 faktor dengan 5 kali ulangan. Faktor ke-1 adalah tingkat naungan yang terdiri dari 3 tingkat yaitu: $\mathrm{N} 0=0 \%$ (tanpa naungan atau dengan penyinaran matahari penuh), $\mathrm{N} 1=25 \%$ naungan dari kerapatan paranet dan $\mathrm{N} 2=50 \%$ naungan dari kerapatan paranet. Faktor ke-2 adalah media tanam yang terdiri dari campuran tanah, pupuk kandang (pukan) dan kompos dengan 6 taraf perbandingan yang berbeda yaitu: $\mathrm{M} 1=1: 0: 0, \mathrm{M} 2=1: 1: 1, \mathrm{M} 3=1: 1: 2, \mathrm{M} 4=$ 3:1:1, M5= 1:2:1, dan M6= 2:1:1.

Pengamatan dimulai sejak penanaman bibit sampai bibit berumur 6 bulan. Pengukuran terhadap parameter pertumbuhan tanaman yang meliputi pertumbuhan tinggi bibit, jumlah daun, diameter batang (diukur dari permukaan media); panjang akar, bobot basah dan kering tajuk, bobot basah dan kering akar, indeks mutu bibit dilakukan pada umur 6 bulan (akhir pengamatan). Perawatan bibit dilakukan dengan melakukan penyiraman setiap hari yaitu 
pada pagi hari, dan pembersihan gulma yang tumbuh di persemaian.

Pengukuran intensitas cahaya pada masing-masing naungan dilakukan dengan alat Lux Meter. Indeks mutu bibit dihitung menurut cara yang dikemukakan oleh Bickelhaupt (1980) serta Lackey dan Alm (1982) dalam Hendromono (1991) sebagai berikut:

Bobot kering tajuk $(\mathrm{g})+$ bobot kering akar $(\mathrm{g})$ $\underset{\text { Bibit }}{\text { Indeks Mutu }=} \frac{\text { Tinggi }(\mathrm{cm})}{\text { Diameter }(\mathrm{mm})}+\frac{\text { bobot kering tajuk }(\mathrm{g})}{\text { bobot kering akar }(\mathrm{g})}$

\section{Hasil dan Pembahasan}

Hasil pengukuran intensitas cahaya pada masing-masing naungan berkisar antara 4.000 34.200 lux (pagi hari), 11.000 - 60.400 lux (siang hari) dan 2.600-23.300 lux (sore hari), selengkapnya disajikan pada Tabel 1 .

\section{Tinggi bibit, jumlah daun dan diameter batang}

Hasil analisis secara statistik menunjukkan bahwa intensitas naungan berpengaruh nyata terhadap pertumbuhan bibit
$P$. javanica Blume. Intensitas cahaya penuh (N0) dapat mempercepat dan meningkatkan pertumbuhan bibit secara nyata. Dari hasil pengamatan tampak parameter tinggi bibit, jumlah daun dan diameter batang meningkat secara gradasi dengan meningkatnya intensitas penyinaran matahari atau sebaliknya yaitu semakin bertambahnya intensitas naungan terlihat pertumbuhan bibit semakin menurun (Tabel 2).

Perlakuan N0 (tanpa naungan) artinya dengan intensitas cahaya rata-rata paling tinggi (39300 lux), memberikan respon positif terhadap pertumbuhan bibit dan menghasilkan ukuran bibit paling tinggi $(27,11 \mathrm{~cm})$, jumlah daun paling banyak (15,57 helai) dan diameter batang paling besar $(4,32 \mathrm{~mm})$. Sedangkan N1 (naungan 25\%, intensitas cahaya rata-rata 16430 lux) menghasilkan pertumbuhan bibit lebih rendah dengan tinggi bibit, jumlah daun dan diameter batang berturut-turut yaitu 21,04 $\mathrm{cm}, 11,50$ helai, $3,25 \mathrm{~mm}$ dan pada $\mathrm{N} 2$ (naungan 50\%, intensitas cahaya rata-rata 5867 lux ) menghasilkan ukuran bibit paling rendah $(17,07 \mathrm{~cm})$, jumlah daun paling sedikit $(7,52$ helai) dan diameter batang paling kecil $(2,68$ $\mathrm{mm})$.

Tabel 1. Hasil pengukuran intensitas cahaya (Lux) pada masing-masing naungan.

\begin{tabular}{cccccc}
\hline \hline $\begin{array}{c}\text { Naungan } \\
(\boldsymbol{\%})\end{array}$ & $\begin{array}{c}\text { Pagi } \\
\text { Pk. 08.00 }\end{array}$ & $\begin{array}{c}\text { Waktu pengukuran } \\
\text { Siang } \\
\text { Pk. 12.00 }\end{array}$ & $\begin{array}{c}\text { Sore } \\
\text { Pk. 15.00 }\end{array}$ & $\begin{array}{c}\text { Total dari 3x } \\
\text { pengukuran } \\
\text { (Lux) }\end{array}$ & $\begin{array}{c}\text { Rata-rata } \\
\text { (Lux) }\end{array}$ \\
\hline \hline N0: 0 & 34200 & 60400 & 23300 & 117900 & 39300 \\
N1: 25 & 11300 & 27000 & 11000 & 49300 & 16430 \\
N2: 50 & 4000 & 11000 & 2600 & 17600 & 5867 \\
\hline \hline
\end{tabular}

Keterangan: Intensitas cahaya diukur menggunakan alat Lux-Meter.

Tabel 2. Respon pertumbuhan bibit Picrasma javanica Blume terhadap intensitas naungan yang berbeda (pada akhir pengamatan, umur 6 bulan).

\begin{tabular}{cccccccccc}
\hline \hline $\begin{array}{c}\text { Naungan } \\
(\%)\end{array}$ & $\begin{array}{c}\text { TT } \\
(\mathbf{c m})\end{array}$ & $\begin{array}{c}\text { JD } \\
(\mathbf{h e l a i})\end{array}$ & $\begin{array}{c}\text { DB } \\
(\mathbf{m m})\end{array}$ & $\begin{array}{c}\text { BST } \\
(\mathbf{g})\end{array}$ & $\begin{array}{c}\text { BKT } \\
(\mathbf{g})\end{array}$ & $\begin{array}{c}\text { PA } \\
(\mathbf{c m})\end{array}$ & $\begin{array}{c}\text { BSA } \\
(\mathbf{g})\end{array}$ & $\begin{array}{c}\text { BKA } \\
(\mathbf{g})\end{array}$ & IMB \\
\hline & $\left.{ }^{*}\right)$ & $\left.{ }^{*}\right)$ & $\left.{ }^{*}\right)$ & $\left.{ }^{*}\right)$ & $\left.*^{*}\right)$ & $\left.{ }^{*}\right)$ & $\left.{ }^{*}\right)$ & $\left.{ }^{*}\right)$ & \\
$\mathrm{N} 0$ & $27,11^{\mathrm{a}}$ & $15,57^{\mathrm{a}}$ & $4,32^{\mathrm{a}}$ & $4,930^{\mathrm{a}}$ & $1,762^{\mathrm{a}}$ & $15,97^{\mathrm{a}}$ & $1,382^{\mathrm{a}}$ & $0,688^{\mathrm{a}}$ & 0,277 \\
$\mathrm{~N} 1$ & $21,04^{\mathrm{b}}$ & $11,50^{\mathrm{b}}$ & $3,25^{\mathrm{b}}$ & $2,404^{\mathrm{b}}$ & $0,946^{\mathrm{b}}$ & $14,74^{\mathrm{a}}$ & $0,660^{\mathrm{b}}$ & $0,292^{\mathrm{b}}$ & 0,127 \\
$\mathrm{~N} 2$ & $17,07^{\mathrm{c}}$ & $7,52^{\mathrm{c}}$ & $2,68^{\mathrm{b}}$ & $0,644^{\mathrm{c}}$ & $0,258^{\mathrm{c}}$ & $10,99^{\mathrm{b}}$ & $0,201^{\mathrm{c}}$ & $0,089^{\mathrm{c}}$ & 0,040 \\
\hline \hline
\end{tabular}

Keterangan: TT $=$ Tinggi Bibit, JD $=$ Jumlah Daun, BST $=$ Bobot Segar Tajuk, BKT $=$ Bobot Kering Tajuk, DB= Diameter Batang, $\mathrm{PA}=$ Panjang Akar, $\mathrm{BSA}=$ Bobot Segar Akar, BKA= Bobot Kering Akar, $\mathrm{IMB}=$ Index Mutu Bibit.

*) Angka-angka yang diikuti oleh huruf yang sama pada kolom yang sama tidak berbeda nyata pada taraf 0.05 uji jarak Duncan (DMRT). 
Hal ini menunjukkan bahwa jenis tanaman ini mempunyai respon positif terhadap intensitas cahaya penuh. Penyinaran matahari dapat meningkatkan aktivitas fotosintesis yang menghasilkan karbohidrat dan dipergunakan untuk pertumbuhan bibit, terlihat dapat memacu pertumbuhan tinggi, pertambahan jumlah daun dan diameter batang. Namun hal ini tidak berlaku untuk semua jenis bibit tanaman yang lain yaitu jenis tanaman dalam ruangan, misalnya Homalomena humilis (Jack) Hook.f. (Rahman, 2006). Karena setiap tumbuhan mempunyai tanggap yang berbeda terhadap lingkungan yang diberikan (Bannister, 1976). Makin tinggi intensitas cahaya yang diterima oleh bibit Picrasma makin tinggi pula energi yang dihasilkan untuk menambah pertumbuhan bibit. Hal ini disebabkan intensitas penyinaran matahari tersebut sebagai sumber energi dipergunakan secara maksimal untuk pertumbuhan bibit. Demikian pula halnya dengan penggunaan media tumbuh, dapat mempengaruhi pertumbuhan bibit $P$. javanica Blume, namun hasilnya agak bervariasi. Secara umum teramati bahwa perlakuan M5 (1-tanah:2-pupuk kandang:1kompos) memberikan respon yang paling baik terhadap pertumbuhan bibit $P$. javanica Blume bila dibandingkan dengan penggunaan campuran media yang lain (M2, M3, M4 dan
M6) dan berbeda nyata dengan kontrol (M1, media tanah). Hal ini dapat dilihat pada semua peubah yang diamati menunjukkan angka tertinggi (Tabel 3).

Pada Tabel 3 dapat dilihat bahwa perlakuan media berpengaruh nyata terhadap pertumbuhan bibit $P$. javanica Blume kecuali pada pertumbuhan panjang akar. Dari semua perlakuan media yang dicoba menunjukkan bahwa M5 (tanah:pukan:kompos= 1:2:1) dapat meningkatkan pertumbuhan bibit secara nyata dan menghasilkan ukuran bibit paling tinggi $(25,05 \mathrm{~cm})$, jumlah daun paling banyak $(15,57$ helai) dan diameter batang paling besar $(3,89$ $\mathrm{mm})$. Sedangkan tinggi bibit dan jumlah daun pada media M2, M3, M4 dan M6 serta diameter batang pada M2 dan M3 tidak berbeda nyata dengan M1 (tanah, kontrol). Namun demikian, semua perlakuan media dengan campuran tanah+pukan+kompos memiliki angka rataan cenderung lebih tinggi pada semua parameter pertumbuhan yang diamati dibandingkan dengan media tanah saja (M1, kontrol). Ini berarti pada media M1 pertumbuhan bibitnya paling jelek (paling rendah kualitasnya) yaitu menghasilkan ukuran bibit paling rendah $(19,10 \mathrm{~cm})$, jumlah daun paling sedikit $(9,20$ helai) dan diameter batang paling kecil $(2,76 \mathrm{~mm})$.

Tabel 3. Respon pertumbuhan bibit Picrasma javanica Blume terhadap penggunaan media tanam yang berbeda (pada akhir pengamatan, umur 6 bulan).

\begin{tabular}{cccccccccc}
\hline \hline $\begin{array}{c}\text { Media } \\
\text { Tanam }\end{array}$ & $\begin{array}{c}\text { TT } \\
(\mathbf{c m})\end{array}$ & $\begin{array}{c}\text { JD } \\
(\mathbf{h e l a i})\end{array}$ & $\begin{array}{c}\text { DB } \\
(\mathbf{m m})\end{array}$ & $\begin{array}{c}\text { BST } \\
(\mathbf{g})\end{array}$ & $\begin{array}{c}\text { BKT } \\
(\mathbf{g})\end{array}$ & $\begin{array}{c}\text { PA } \\
(\mathbf{c m})\end{array}$ & $\begin{array}{c}\text { BSA } \\
(\mathbf{g})\end{array}$ & $\begin{array}{c}\text { BKA } \\
(\mathbf{g})\end{array}$ & IMB \\
\hline \hline **) & $\left.{ }^{*}\right)$ & $\left.{ }^{*}\right)$ & $\left.{ }^{*}\right)$ & $\left.{ }^{*}\right)$ & $\left.{ }^{*}\right)$ & $\left.{ }^{*}\right)$ & $\left.{ }^{*}\right)$ & $\left.{ }^{*}\right)$ & \\
M1 & $19,10^{\mathrm{b}}$ & $9,20^{\mathrm{b}}$ & $2,76^{\mathrm{c}}$ & $1,767^{\mathrm{b}}$ & $0,663^{\mathrm{b}}$ & $12,71^{\mathrm{a}}$ & $0,476^{\mathrm{b}}$ & $0,221^{\mathrm{b}}$ & 0,089 \\
M2 & $22,15^{\mathrm{ab}}$ & $11,20^{\mathrm{b}}$ & $3,97^{\mathrm{a}}$ & $2,747^{\mathrm{b}}$ & $1,14^{\mathrm{ab}}$ & $12,43^{\mathrm{a}}$ & $0,677^{\mathrm{b}}$ & $0,321^{\mathrm{ab}}$ & 0,160 \\
M3 & $20,73^{\mathrm{b}}$ & $9,20^{\mathrm{b}}$ & $2,85^{\mathrm{c}}$ & $1,975^{\mathrm{b}}$ & $0,737^{\mathrm{b}}$ & $13,01^{\mathrm{a}}$ & $0,630 \mathrm{~b}$ & $0,304^{\mathrm{b}}$ & 0,107 \\
M4 & $21,34^{\mathrm{b}}$ & $11,33^{\mathrm{b}}$ & $3,37^{\mathrm{abc}}$ & $2,153^{\mathrm{b}}$ & $0,793^{\mathrm{b}}$ & $13,99^{\mathrm{a}}$ & $0,605^{\mathrm{b}}$ & $0,297^{\mathrm{b}}$ & 0,121 \\
M5 & $25,05^{\mathrm{a}}$ & $16,53^{\mathrm{a}}$ & $3,89^{\mathrm{a}}$ & $4,573^{\mathrm{a}}$ & $1,58^{\mathrm{a}}$ & $15,23^{\mathrm{a}}$ & $1,213^{\mathrm{a}}$ & $0,514^{\mathrm{a}}$ & 0,220 \\
M6 & $22,43^{\mathrm{ab}}$ & $11,50^{\mathrm{b}}$ & $3,74^{\mathrm{ab}}$ & $2,891^{\mathrm{b}}$ & $1,067^{\mathrm{b}}$ & $16,41^{\mathrm{a}}$ & $0,934^{\mathrm{ab}}$ & $0,509^{\mathrm{a}}$ & 0,195 \\
\hline \hline
\end{tabular}

Keterangan: $\mathrm{TT}=$ Tinggi Bibit, $\mathrm{JD}=$ Jumlah Daun, BST $=$ Bobot Segar Tajuk, BKT $=$ Bobot Kering Tajuk, $\mathrm{DB}=$ Diameter Batang, $\mathrm{PA}=$ Panjang Akar, $\mathrm{BSA}=$ Bobot Segar Akar, BKA= Bobot Kering Akar, $\mathrm{IMB}=$ Indekss Mutu Bibit.

*) Angka-angka diikuti huruf yang sama pada kolom yang sama tidak berbeda nyata pada taraf 0,05 uji jarak Duncan.

**) Media tanam: campuran dari (tanah:pukan:kompos); M1= 1:0:0, M2=1:1:1, M3=1:1:2, M4= $3: 1: 1$, M5 $=1: 2: 1$, dan M6= 2:1:1. 
Terlihat ada peningkatan pertumbuhan vegetatif dari bibit Picrasma pada penggunaan media yang mengandung pupuk-kandang dan kompos dari pada media tanah murni. Pemakaian media dengan pupuk kandang lebih banyak terlihat paling baik yaitu pada perlakuan M5 (1:2:1), dari pada media dengan komposisi kompos yang lebih banyak yaitu pada perlakuan M3 (1:1:2). Menurut Lakitan (1995) media kompos mempunyai sifat-sifat sebagai berikut, bobot spesifik $224 \mathrm{~kg} / \mathrm{m} 3$, tidak steril, $\mathrm{pH}$ berkisar antara 5,5 - 8,5, status hara rendah NPK, $\mathrm{Ca}$ dan $\mathrm{Mg}$, kapasitas penyangga sedang - tinggi, kapasitas pegang air baik, pertukaran kation tinggi, aerasi baik, ukuran partikel 1,6-13,0 mm. Kandungan N, P dan $\mathrm{K}$ pada pupuk kandang umumnya tidak terlalu tinggi namun dapat memperbaiki permeabilitas tanah, porositas, struktur tanah, porositas, struktur tanah, daya menahan air dan kandungan kation tanah (Hardjowigeno,1995; Santosa, 1975).

Media tanah (M1, kontrol) yang tidak menggunakan campuran baik pupuk kandang maupun kompos cenderung terlihat kurang memberikan respon yang baik dan menghasilkan angka yang paling rendah terhadap semua parameter pertumbuhan bibit yaitu tinggi tanaman, jumlah daun, diameter batang dan panjang akar. Hal ini bisa dimengerti bahwa media tanah murni kurang menyediakan nutrisi untuk pertumbuhan bibit Picrasma. Pertumbuhan bibit akan lebih baik dengan penambahan nutrisi yaitu dengan penambahan pupuk kandang ataupun kompos. Hasil ini didukung dengan analisa kandungan unsur hara pada M1 yang menunjukkan persentasenya paling rendah yaitu $\mathrm{N} 0,20 \%, \mathrm{P}$ $0,21 \%, \mathrm{~K} \quad 0,03 \%$ dan ratio $\mathrm{C} / \mathrm{N} 2,86$ dibandingkan pada media M2, M3, M4, M5 dan M6. Sedangkan kandungan N, P, K dan ratio $\mathrm{C} / \mathrm{N}$ pada media $\mathrm{M} 5$ berurut-turut adalah 0,44\%, 0,33\%, 0,15\% dan 11,41 (Tabel 4).

Kombinasi perlakuan naungan dan media memberikan respon yang bervariasi terhadap pertumbuhan bibit $P$. javanica, namun tampak bahwa kombinasi tanpa naungan (N0) dengan semua variasi media yang dicoba tampak menghasilkan pertumbuhan yang lebih baik dibandingkan dengan kombinasi antara naungan $25 \% \quad(\mathrm{~N} 1)$ dan $50 \%$ (N2). Pada kombinasi N0 dengan M1, M2, M3, M4, M5 dan M6 menghasilkan rataan tinggi tanaman berkisar antara $18,10-36,14 \mathrm{~cm}$, jumlah daun 10,60 - 28,2, diameter batang 3,4-4,7 mm, panjang akar 11,60 - 16,7 cm, bila dibandingkan dengan kombinasi perlakuan lainnya, seperti yang disajikan pada Tabel 5 .

Pada Tabel 5 dapat dilihat bahwa pertumbuhan bibit paling baik tampak pada kombinasi perlakuan N0 (tanpa naungan) dengan media M5 (1:2:1) yang menghasilkan ukuran bibit paling tinggi $(36,14 \mathrm{~cm})$, jumlah daun paling banyak (28,20 helai) dan ukuran diameter batang paling besar $(4,9 \mathrm{~mm})$. Media campuran tanah:pukan:kompos dengan komposisi perbandingan pupuk kandang lebih banyak menghasilkan pertumbuhan paling baik. Pada kondisi intensitas cahaya tinggi akan menghasilkan fontosintitat tinggi didukung dengan kandungan hara yang cukup pada media sehingga pertumbuhan bibit maksimal.

\section{Panjang akar, bobot segar dan kering tajuk, bobot segar dan kering akar}

Pada Tabel 2 dapat dilihat bahwa perlakuan tanpa naungan (N0) menghasikan ukuran akar terpanjang $(15,97 \mathrm{~cm})$ diikuti dengan naungan $25 \%$ (N1) $14,74 \mathrm{~cm}$ dan keduanya berbeda nyata dengan naungan $50 \%$ (N2) yang ukuran akarnya terpendek (10,99 $\mathrm{cm})$. Intensitas naungan berpengaruh nyata terhadap bobot segar dan bobot kering tajuk, bobot segar dan kering akar. Perlakuan tanpa naungan (intensitas cahaya rata-rata 39300 lux) menghasilkan bobot kering tajuk dan akar paling tinggi, yakni berturut-turut $1,762 \mathrm{~g}$ dan $0,688 \mathrm{~g}$ yang berbeda nyata dengan naungan $25 \%$, intensitas cahaya rata-rata 16430 lux (masing-masing 0,946 g dan 0,292 g) dan naungan $50 \%$, intensitas cahaya rata-rata 5867 lux $(0,258 \mathrm{~g}$ dan $0,089 \mathrm{~g})$. Beberapa jenis tanaman mempunyai respon positif terhadap intensitas cahaya tinggi dan dapat meningkatkan bobot kering tajuk dan akar secara nyata, seperti pada Gynura procumbens (Utami, 2000), Sonchus arvensis (Hartutiningsih dan Utami, 2000). Laju fotosintesis meningkat dan bobot kering tanaman bertambah seiring dengan semakin tinggi intensitas cahaya (Gardner et al., 1991). 
Tabel 4. Analisa kandungan hara pada berbagai media tanam.

\begin{tabular}{|c|c|c|c|c|c|}
\hline \multirow[t]{2}{*}{ Media Tanam } & \multicolumn{5}{|c|}{ Unsur Hara } \\
\hline & $\mathrm{N}(\%)$ & $\mathbf{P}(\%)$ & $\mathbf{K}(\%)$ & $\mathrm{C}(\%)$ & $\mathrm{C} / \mathrm{N}$ \\
\hline M1 & 0,20 & 0,21 & 0,03 & 0,57 & 2,86 \\
\hline M2 & 0,33 & 0,32 & 0,13 & 3,82 & 11,66 \\
\hline M3 & 0,44 & 0,43 & 0,14 & 7,34 & 16,61 \\
\hline M4 & 0,31 & 0,29 & 0,09 & 3,31 & 10,59 \\
\hline M5 & 0,44 & 0,33 & 0,15 & 5,04 & 11,41 \\
\hline M6 & 0,35 & 0,35 & 0,12 & 5,15 & 14,69 \\
\hline
\end{tabular}

Catatan: Media tanam: campuran dari (tanah:pupuk-kandang:kompos); M1=1:0:0, M2=1:1:1, M3=1:1:2, M4= $3: 1: 1$, M5 $=1: 2: 1$, dan M6= 2:1:1.

Tabel 5. Respon pertumbuhan bibit Picrasma javanica Blume terhadap intensitas naungan dan media tanam yang berbeda (pada akhir pengamatan, umur 6 bulan).

\begin{tabular}{clcccccccc}
\hline \hline $\begin{array}{c}\text { Naungan } \\
(\%)\end{array}$ & $\begin{array}{c}\text { Media } \\
\text { Tanam }\end{array}$ & $\begin{array}{c}\text { TT } \\
(\mathbf{c m})\end{array}$ & $\begin{array}{c}\text { JD } \\
\text { (helai) }\end{array}$ & $\begin{array}{c}\text { DB } \\
(\mathbf{m m})\end{array}$ & $\begin{array}{c}\text { BST } \\
(\mathbf{g})\end{array}$ & $\begin{array}{c}\text { BKT } \\
(\mathbf{g})\end{array}$ & $\begin{array}{c}\text { PA } \\
(\mathbf{c m})\end{array}$ & $\begin{array}{c}\text { BSA } \\
(\mathbf{g})\end{array}$ & $\begin{array}{c}\text { BKA } \\
(\mathbf{g})\end{array}$ \\
\hline \hline N0 & M1 & 18,10 & 10,60 & 3,4 & 2,70 & 0,94 & 15,60 & 0,64 & 0,35 \\
& M2 & 28,30 & 14,80 & 4,9 & 4,88 & 1,84 & 14,10 & 1,44 & 0,72 \\
& M3 & 27,40 & 13,80 & 4,3 & 4,46 & 1,58 & 16,34 & 1,34 & 0,62 \\
& M4 & 25,20 & 12,80 & 4,2 & 3,58 & 1,22 & 11,60 & 0,92 & 0,48 \\
& M5 & 36,14 & 28,20 & 4,9 & 8,54 & 3,00 & 16,70 & 2,12 & 0,92 \\
& M6 & 27,52 & 13,20 & 4,3 & 5,42 & 1,99 & 14,30 & 1,83 & 1,04 \\
\hline N1 & M1 & 22,80 & 10,00 & 2,9 & 2,20 & 0,88 & 13,84 & 0,50 & 0,19 \\
& M2 & 21,10 & 11,20 & 2,9 & 2,68 & 1,28 & 13,70 & 0,44 & 0,17 \\
& M3 & 18,94 & 9,60 & 2,5 & 1,17 & 0,46 & 13,76 & 0,46 & 0,24 \\
& M4 & 20,72 & 13,20 & 3,7 & 2,10 & 0,82 & 18,32 & 0,72 & 0,32 \\
& M5 & 20,72 & 12,60 & 4,3 & 4,30 & 1,46 & 13,02 & 1,22 & 0,52 \\
& M6 & 21,98 & 12,40 & 3,2 & 1,98 & 0,78 & 23,20 & 0,62 & 0,31 \\
\hline N2 & M1 & 16,40 & 7,00 & 2,0 & 0,40 & 0,17 & 8,88 & 0,29 & 0,12 \\
& M2 & 17,06 & 7,60 & 4,1 & 0,68 & 0,31 & 9,50 & 0,15 & 0,07 \\
& M3 & 15,84 & 5,60 & 1,7 & 0,30 & 0,18 & 8,92 & 0,09 & 0,05 \\
& M4 & 18,10 & 8,00 & 2,3 & 0,78 & 0,34 & 12,04 & 0,17 & 0,09 \\
& M5 & 18,30 & 8,80 & 2,7 & 0,88 & 0,28 & 15,96 & 0,30 & 0,10 \\
& M6 & 8,00 & 0,84 & 4,4 & 0,26 & 0,37 & 2,06 & 0,10 & 0,08 \\
\hline \hline
\end{tabular}

Catatan: TT $=$ Tinggi Bibit, JD $=$ Jumlah Daun, BST $=$ Bobot Segar Tajuk, BKT $=$ Bobot Kering Tajuk, DB= Diameter Batang, PA= Panjang Akar, BSA= Bobot Segar Akar, BKA= Bobot Kering Akar.

Pada Tabel 3 dapat diamati bahwa perlakuan media M5 (tanah : pukan : kompos = 1:2:1) menghasilkan angka tertinggi pada bobot segar tajuk 4,573 $\mathrm{g}$ dan bobot kering tajuk 1,58 $\mathrm{g}$, bobot segar akar 1,213 g dan bobot kering akar 0,514 g dan berbeda nyata dengan M1 (media tanah). Panjang akar tidak dipengaruhi oleh perlakuan media, namun pada M5 memiliki panjang akar 15,23 cm yang cenderung lebih panjang dibandingkan M1, M2, M3 dan M4. Akar berpengaruh terhadap penyerapan air dan unsur hara untuk proses pertumbuhan lebih lanjut sehingga merupakan bagian integral dari tanaman (Kolek dan Konzink, 1993). Pupuk organik umumnya mengandung unsur hara makro dan sejumlah kecil unsur hara mikro yang berguna untuk pertumbuhan tanaman. Pupuk organik dapat memperbaiki struktur tanah, kemantapan agregat, daya pegang air dan permeabilitas tanah serta meningkatkan nilai tukar kation, menyediakan hara dan meningkatkan aktivitas makroorganisme tanah (Yufdi, 1996).

Seperti halnya pada pertumbuhan tinggi, jumlah daun dan diameter batang, pada Tabel 5 dapat diamati bahwa kombinasi perlakuan 
N0M5 memberikan hasil terbaik pada bobot segar tajuk 8,54 g dan bobot kering tajuk $3 \mathrm{~g}$, bobot segar akar 2,12 g dan bobot kering akar $0,92 \mathrm{~g}$, panjang akar $16,70 \mathrm{~cm}$. Kombinasi perlakuan N0M5 merupakan kombinasi yang ideal untuk meningkatkan pertumbuhan bibit ki pahit. Penelitian pada Mentha arvensis menunjukkan bahwa kombinasi perlakuan tanpa naungan dan media campuran tanah:pukan:kompos $\quad(1: 1: 1)$ menghasilkan produktivitas yang paling baik dibandingkan media lain (Utami dan Hartutiningsih, 2001). Laju fotosintesa yang tinggi didukung dengan media yang cocok akan menghasilkan senyawa penting untuk pertumbuhan (karbohidrat, protein, lemak dan bahan-bahan organik lainnya), sedangkan $80-90 \%$ bobot kering tanaman berasal dari karbon hasil fotosintesis (Salisbury dan Ross, 1991).

\section{Indeks mutu bibit}

Pada Tabel 2 dapat diamati bahwa semakin tinggi intensitas cahaya maka indeks mutu bibit meningkat secara gradasi, untuk N0, $\mathrm{N} 1$ dan N2 berturut-turut adalah 0,$277 ; 0,127$ dan 0,040. Hal ini dapat dimengerti karena indeks mutu bibit merupakan perpaduan antara bobot kering tajuk, akar, tinggi bibit dan diameter batang. Bobot kering tajuk dan akar yang semakin tinggi akan menghasilkan indeks mutu bibit yang tinggi pula. Perlakuan media menghasilkan indeks mutu bibit yang bervariasi yaitu berkisar 0,089 - 0,220; media M5 (tanah : pukan : kompos $=1: 2: 1$ ) menghasilkan indeks mutu bibit paling tinggi dan paling rendah pada M1 (tanah).

Dari hasil analisa komponen unsur hara pada M5 yang terdiri dari N $0,44 \%, \mathrm{P} 0,33 \%, \mathrm{~K}$ 0,15\%, Carbon 5,04 dan C/N 11,41 merupakan komposisi yang seimbang untuk menghasilkan indeks mutu bibit yang tinggi dibandingkan dengan M1 dengan kandungan $\mathrm{N} \mathrm{0,20 \% ,P}$ $0,21 \%, \mathrm{~K} 0,03 \%, \mathrm{C} 0,57 \%$ dan $\mathrm{C} / \mathrm{N} 2,86$ yang kurang mencukupi untuk pertumbuhan bibit yang baik. Kombinasi perlakuan terbaik adalah N0M5 yang menghasikan indeks mutu bibit paling tinggi yaitu 0,92 . Komponen unsur hara yang terkandung dalam media dengan perbandingan tertentu antara nitrogen $(\mathrm{N})$, kalium (K), Pospor (P) sangat diperlukan bagi pertumbuhan vegetatif tanaman (Santosa,
1975). Bahan organik selain memperbaiki struktur tanah menjadi lebih gembur, kemantapan agregat, daya pegang air serta permeabilitas tanah juga meningkatkan ketersediaan unsur hara (Kononova, 1996).

\section{Kesimpulan}

Intensitas naungan berpengaruh nyata terhadap pertumbuhan bibit, semakin tinggi intensitas naungan, semakin menurunkan pertumbuhan bibit Picrasma. Pertumbuhan bibit $P$. javanica Blume paling baik tanpa naungan. Media tanam berpengaruh nyata terhadap pertumbuhan bibit $P$. javanica Blume, media dengan komposisi tanah + pukan + kompos menghasilkan pertumbuhan bibit paling baik. Kombinasi perlakuan tanpa naungan dengan media campuran tanah:pukan: kompos memberikan pertumbuhan bibit $P$. Javanica Blume paling baik.

\section{Ucapan Terima Kasih}

Penulis mengucapkan terima kasih kepada Puslit Biologi LIPI, yang telah memberikan fasilitas untuk penelitian ini, juga kepada Ibu Sri Rahayu dan Ibu A'ah yang telah membantu dalam pelaksanaan penelitian ini. Ucapan terima kasih juga kami tujukan kepada Bapak Prof. Dr. Hadi Sutarno yang telah bersedia memeriksa naskah ini.

\section{Daftar Pustaka}

Arbain, D., Byrne, L.T., Sargent, B.W. and White, A.H. 2005. The Alkaloid of Picrasma javanica: Further Studies. http://www.ncbi.nlm.nih.gov/ sites/entrezdb $=$ pubmed\&listuids $=11395264 \&$ cmd=Rtetrieve\&ndexed. 08/20/2007.

Baharsyah, S. 1996. Bioteknologi dan Gerakan Nasional Agroindustri sebagai Wahana Pengembangan Pedesaan. Pross. Sem. Nas. Bioteknologi Pertanian Paket Bioteknologi Dalam Menunjang Gerakan Nasional Agroindustri Di Pedesaan. Pusat Bioteknologi Pertanian Universitas Muhamadiyah. Malang.

Bahktiar, A. 2005. Aneka Tumbuhan Obat di Indonesia Bisa Punah. URL: http://www.gatra.com/ versi_cetak.php?id=86275. 04/27/2006 
Bannister, P. 1976. Introduction to Physiological Plant Ecology Blackweel Scientific Publication Oxford London Edinburg Melbourne.

Hardjowigeno. 1995. Ilmu Tanah. Penerbit CV. Akademika Presindo: Jakarta

Hartmann, H.T., Kester, D.E. and Davies, F.T. 1997. Plant Propagation. Principles \& Practices. Fift Edition. Prentice. Hall. International. Inc. New Jersey.

Hartutiningsih, M.S. dan Utami, N.W. 2000. Budidaya Tempuyung (Sonchus arvensis): Respon Intensitas Cahaya dan Pemupukan. Pros. Seminar PERHIBA.

Hendromono. 1991. Pertumbuhan dan Mutu Bibit Eboni (Diospyros celebica Bakh.) Pada Tiga Jenis Medium yang dipupuk NPK. J. Penelitian dan Pengembangan Kehutanan VII (1): 28-31.

Heyne, K. 1987. Tumbuhan Berguna Indonesia II. Cetakan 1. Badan Litbang Kehutanan, Jakarta.

Hidayat, S. 2003. Picrasma javanica Blume. In: Lemmens, R.H.M.J. and Bunyapraphatsara, N. (Eds.). Medicinal and Poisonous Plant 3, PROSEA, Plant Resources of South-East Asia No. 12 (3). pp. 329-330. Backhuys Publishes, Leiden.

Gardner, F.P., Pearce, R.B. dan Mitchell, R.L. 1991. Fisiologi Tanaman Budidaya, Penerbit Universitas Indonesia.

Kolek, J. and Konzink, D. 1993. Physiology of The Plant Root System. Kluwer Academic Publishers.

Kononova, M.M. 1996. Soil Organik Matter Its Role in Soil Formation and soil Fertility. Pergamon Press, New York, USA, 544 p.

Lakitan, B. 1995. Hortikultura: Teori, Budidaya \& Pasca Panen. PT. Raja Gafindo Persada. Jakarta.

Praptiwi, Harapini, M. dan Chairul. 2007. Uji Aktivitas Antimalaria secara In-Vivo Ekstrak Ki Pahit (Picrasma javanica) pada Mencit yang Diinfeksi Plasmodium berghei. J. of Biological Diversity (8) 2: 113-114.

Rahman, E. 2006. Homalomena humilis (Jack) Hook.f. dalam Tanaman Hias Dalam Ruangan di Indinesia. Sutarno, H. et al., (Eds.). Sumber Daya Nabati No. 20.1. Pusat Penelitian Biologi, LIPI. Hal. 76-77.
Santosa. 1975. Ilmu Hara, Fakultas Biologi, Universitas Gadjah Mada. Yogyakarta.

Salisbury, F.B. and Ross, C.W. 1991. Plant Physiology. Fourth Edition. Wodsworth Publishing Company Belmont, California.

Sutarno, H. and Utami, N.W. 2007. Germination and Seedling Vigor of Picrasma javanica BLUME at Various Temperatures. Pross. Sem. Nas. XIII PERSADA.

Uji, T. 1995. Pemanfaatan Tumbuhan Obat Antimalaria pada Beberapa Suku di Indonesia. Pross. Sem. dan Lokakarya Nasional Etnobotani II. Yogyakarta. Nasution, RE et al., (Eds.). Jakarta, Ikatan Pustakawan Indonesia. Hal: 89-95.

Utami, N.W. 2000. Produktivitas Gynura procumbens (L.) Merr. pada Berbagai Media Tumbuh dan Tingkat Naungan. J. Ilmiah Pertanian Gakuryoku VI (1): 28-31.

Utami, N.W. dan Hartutiningsih. 2001. Produktivitas Tanaman Poko (Mentha arvensis L.) pada Berbagai Media Tumbuh dan Intensitas Cahaya yang Berbeda. Pross. Sem. Nas. II Tumbuhan Obat dan Aromatik APINMAP. 316-321.

Wirdateti dan Roemantyo, S.H. 1992. Pemanfaatan Tumbuhan Obat untuk Pengobatan Tradisional, Penyakit Rakyat di Dumoga Bone, Sulawesi Utara. Pross. Sem. Nas. dan Lokakarya Etnobotani. Cisarua-Bogor. Nasution, R.E.; S.Riswan; P. Tjitropranoto; E.B. Waluyo; W. Martowikrido; H. Roemantyo \& S.S. Wardoyo (Eds.). Jakarta, Perpustakaan Nasional R.I. Hal: 106-118

Yufdy, P. 1996. Pengaruh Berbagai Jenis Bahan Organik terhadap Pertumbuh Rose. Pros. Simposium Nas. Tumbuhan Obat dan Aromatik, APINMAP. 